\title{
An unusual right popliteal vein aneurysm in an adult cadaver: A case report
}

\author{
Suhani Sumalatha, Antony Sylvan D Souza, Kumar MR Bhat, Nandhini Bhat, Mamatha \\ Hosapatna, Sushma R Kotian
}

Department of Anatomy, Kasturba Medical College, Manipal University, Manipal, India

\section{CASE REPORT}

Please cite this paper as: Sumalatha $S$, Souza ASD, Bhat KMR, Bhat N, Hosapatna M, Kotian SR. An unusual right popliteal vein aneurysm in an adult: $A$ case report. AMJ 2014, 7, 6, 260-263. http://doi.org/10.21767/AMJ.2014.2128

\section{Corresponding Author:}

Sushma R Kotian

Lecturer

Dept. of Anatomy, Kasturba Medical Collage

Manipal University, Manipal-576104, India

Phone- +91-820-2922327 (Office)

Email: sushma.rk@manipal.edu

\section{ABSTRACT}

The incidence of venous aneurysm is less than arterial aneurysms. Most are incidental findings with no major clinical significance. However, popliteal vein aneurysms (PVA) may be potentially life threatening, as they can be a source of pulmonary embolism and potentially even death. We report a case of right PVA in a 67-year-old male cadaver. Information from this case study may contribute to an improved understanding of these phenomena, including early detection of these or similar thromboembolic events.

\section{Key Words}

Popliteal vein, aneurysm, popliteal fossa, pulmonary embolism

\section{Implications for Practice:}

\section{What is known about this subject?}

PVAs may be potentially life threatening, as they can be a source of pulmonary embolism.

\section{What new information is offered in this study?}

A large and saccular PVA was observed in the right inferior extremity of a cadaver, which is extremely rare.
3. What are the implications for research, policy, or practice?

This case report explains the variability in the existence of the PVA and stresses the use of non-invasive diagnostic methods like ultrasound, $\mathrm{CT}$, and $\mathrm{MRI}$ to detect the otherwise unnoticed aneurysms, and to plan the treatment regime accordingly. They should also be considered during different surgical interventions in the popliteal region.

\section{Background}

Aneurysms in the venous system are rare and less common than arterial aneurysms. Most are incidental findings with no major clinical significance. However, PVAs are an exception. Their presence may be life threatening as they can cause pulmonary embolism (PE) and even death. ${ }^{1}$

The popliteal vein (PV) is formed by the deep veins of the leg beyond the adductor hiatus, and continues as the femoral vein. In the popliteal fossa, the vein accompanies the popliteal artery but undergoes a less oblique course such that the upper part the vein lies posterolateral to the artery, then crosses behind (superficial to) the artery before running medial to the artery. In the middle of the popliteal fossa, the vein is sandwiched between the artery and the tibial nerve.

The diagnosis of a PVA is difficult as there are no characteristic signs and symptoms directly associated with the aneurysm. Most cases come to light during incidental findings or when a pulmonary embolism or other thromboembolic episodes presents to a clinician, and less commonly because of a mass in the popliteal fossa, calf swelling, or pain. ${ }^{2-5}$ PVA can, however, be detected by recently advanced imaging techniques and thereby managed effectively.

Here we present a rare case of the right PVA without any other associated variations in an adult cadaver of south Indian race. 


\section{Case details}

During routine cadaveric dissection of the right lower limb of a 67-year-old male cadaver, in the Department of Anatomy, Kasturba Medical College, Manipal, an unusual variation was discovered. The popliteal fossa was meticulously dissected to expose its contents. Interestingly, a large and saccular dilatation was observed in the popliteal vein distal to the adductor hiatus over the popliteal surface of the femur. This aneurysm of the popliteal vein was $6 \mathrm{~cm}$ long and $3.5 \mathrm{~cm}$ wide. The formation, course, and termination of the popliteal vein were otherwise normal. The popliteal artery was situated deep to the vein and the tibial, and common peroneal branches of the sciatic nerve were located lateral to it. The small saphenous vein was also observed to be draining into the popliteal vein at its dilatation after piercing the posterior wall of the popliteal fossa (Figure 1). No other associated variations were observed.

Figure 1: Large and saccular popliteal vein aneurysm (PVA) in the right popliteal fossa

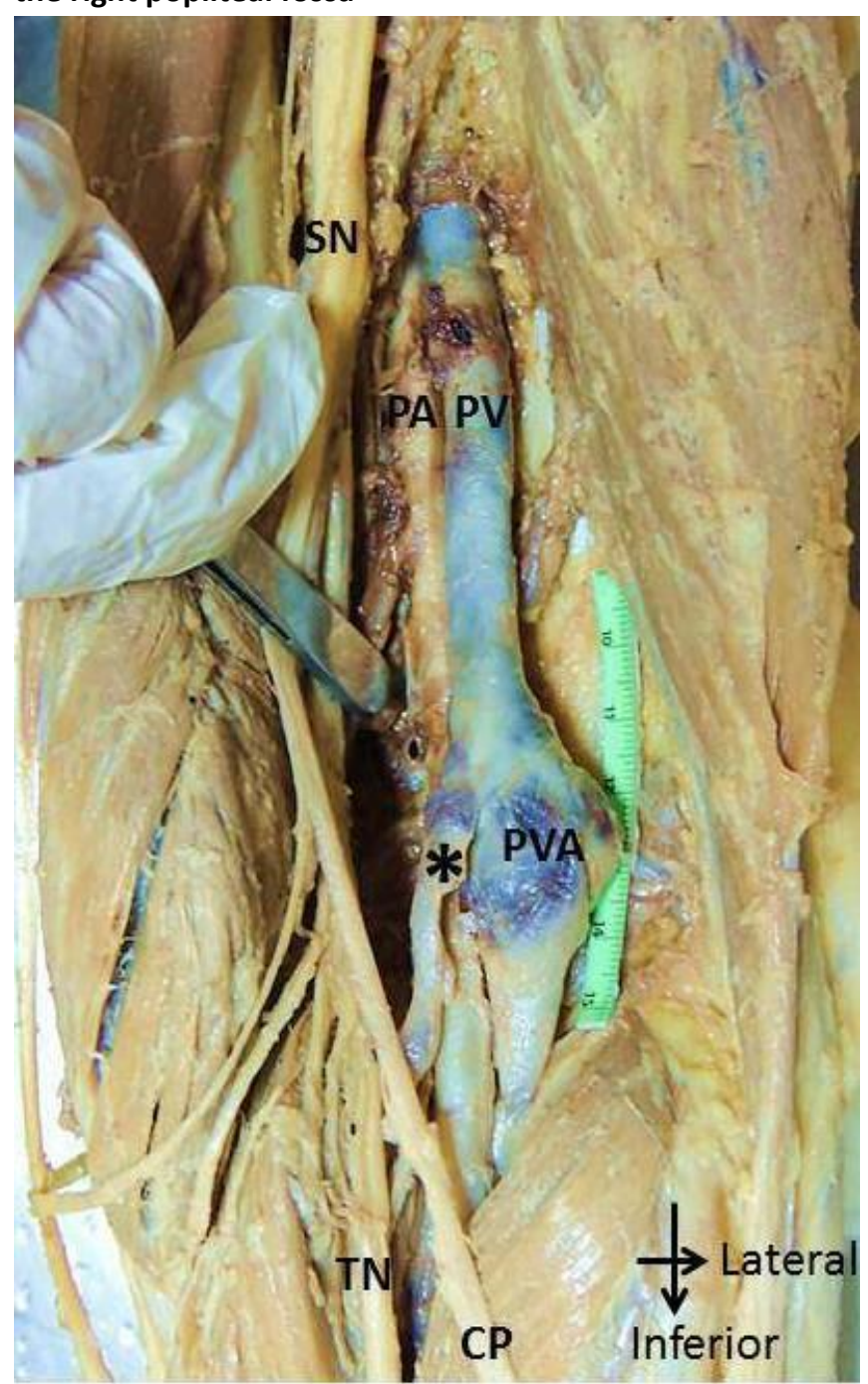

PV: popliteal vein, PA: popliteal artery, SN: sciatic nerve, TN: tibial nerve, CP: common peroneal nerve, *: short saphenous vein draining into $P V$ at the site of the aneurysm.

\section{Discussion}

The incidence of the venous aneurysm is less common than the arterial aneurysm. ${ }^{6}$ In 77 per cent of cases they are reported in the lower limb, 13 per cent in veins of the neck like the internal jugular vein, and in 10 per cent of the cases they are seen in the upper $\operatorname{limb}{ }^{7}$ Although PVA is rare, the involvement of the PV in aneurysms is more often reported than the great saphenous vein and the veins of the foot. ${ }^{7}$ The PVA is usually unilateral, and is present more often in the proximal part of the PV. ${ }^{4,8}$ PVAs can occur at any age and females are more often affected than males. ${ }^{4}$ In the present case, the aneurysm was observed in the distal part of the PV in the right lower limb of an adult male cadaver.

Venous aneurysms are broadly classified into primary and secondary. Most PVAs are true aneurysms, involving all three layers (tunica) of the normal vein. ${ }^{3}$ They are usually unilateral, and as many as 75 per cent are saccular. ${ }^{4}$ Trauma, congenital vein wall weakness, inflammation, and localised degenerative changes have been considered as possible risk factors for the development of PVAs, but the exact pathogenesis of these aneurysms is unclear. ${ }^{3,9}$

Sessa et al. classified venous aneurysms as saccular (72 per cent) and fusiform (28 per cent) based on the shape of the aneurysm. The saccular type was more common and was found to be more prone for intraluminal thrombus (40 per cent) than fusiform aneurysms (14 per cent). ${ }^{4}$

In most cases, venous aneurysms are asymptomatic and are mostly found incidentally; ${ }^{5}$ however, the PVA is generally an exception. The association between PVAs, thromboembolic events, and recurrent pulmonary emboli has been well documented in adults. ${ }^{4,5,10}$

PVA can also be elicited as a soft, painful popliteal mass in clinical examination as reported in 26 per cent of the cases in a review by Bergqvist et al. ${ }^{5}$ Catherine et al. reported a unique case of PVA in a patient presenting with chronic calf muscle pain and atrophy. ${ }^{11}$ Thus, a majority of the cases of PVA are reportedly seen in living patients and are symptomatic, with the most common symptoms being pulmonary embolism and postthrombotic syndrome. ${ }^{2-11}$ However, PVAs may sometimes remain completely unnoticed and may be encountered during cadaveric dissection as reported in this case. Although the existence of PVAs in cadavers is scarcely reported, one case in the available literature has mentioned the existence of PVA in the form of two fusiform dilatations. ${ }^{12}$ 
Complications of PVAs are mainly pulmonary embolism (24 per cent) or chronic venous diseases (76 per cent) involving limb swelling, varicosities, and venous ulcer as reported by Sessa et al. ${ }^{4}$ Lawrence et al. reported ilio-femoral thrombosis as one of the complication of PVA. ${ }^{13}$

The PVA can be diagnosed by various non-invasive methods like ultrasound using duplex and colour Doppler imaging, CT, and MRI scans. ${ }^{14}$ The use of venous duplex scanning enables one to detect the occurrence of PVAs in patients with deep or superficial vein insufficiency. Labropoulos et al. identified seven cases of asymptomatic PVAs through the colour flow Duplex imaging method. In their study, all the aneurysm were of a saccular type, fully compressible, without evidence of thrombus in the sac, and with a maximal diameter ranging from 2.0 to $2.8 \mathrm{~cm}$. Superficial vein incompetence was found in six patients. ${ }^{15}$

CT and MRI have also proved to be highly effective in detecting PVAs, as they are more accurate and can even identify the size and extent of the lesion and its vascular origin. ${ }^{16}$

PVAs are uncommon but are a potential source of serious thromboembolic complications. They could be dangerous, lifethreatening and a source of pulmonary embolism, including the ones that are asymptomatic or those having an unpredictable course; therefore, surgery is the treatment of choice for this pathology. ${ }^{4}$ Patients with asymptomatic saccular or large $(>20 \mathrm{~mm})$ fusiform aneurysms should also be treated surgically, regardless of the presence of thrombus, because of the unpredictable risk of thromboembolic complication. ${ }^{4}$ However, small fusiform aneurysm without any thromboembolic complications can be followed up under close monitoring with duplex scanning. ${ }^{4,17}$

Early diagnosis of the PVA is therefore essential in order to prevent the thromboembolic events or other major complications. The diagnosis of a PVA should be considered not only in patients with an intractable pulmonary embolism, but also in those who have unexplained popliteal pain and ipsilateral lower extremity muscle atrophy. This case report explains one such PVA and stresses the use of non-invasive diagnostic methods like ultrasound, $\mathrm{CT}$, and MRI to detect the otherwise unnoticed aneurysms and to plan the appropriate treatment regimen accordingly.

\section{References}

1. Greenwood LH, Yrizarry JM, Hallett JW Jr. Peripheral venous aneurysms with recurrent pulmonary embolism: report of a case and review of the literature. Cardiovasc Intervent Radiol 1982; 5:43-45.

2. Sigg $\mathrm{P}$, Koella $\mathrm{C}$, Stobe $\mathrm{C}$, Jeanneret $\mathrm{C}$. Popliteal venous aneurysm: a cause of pulmonary embolism. VASA 2003;32:221-24.

3. Coffman SW, Leon SM, Gupta SK. Popliteal venous aneurysms: report of an unusual presentation and literature review. Ann Vasc Surg 2000;14:286-290.

4. Sessa C, Nicolini P, Perrin M, Farah I, Magne J, Guidicelli $H$. Management of symptomatic and asymptomatic popliteal venous aneurysms: a retrospective analysis of 25 patients and review of the literature. J Vasc Surg 2002;32:902-12.

5. Bergqvist $D$, Bjorck $M$, Ljungman $C$. Popliteal venous aneurysm: a systematic review. World J Surg 2006;30: 273-79.

6. Friedman SG, Krishnasastry KV, Doscher W, Deckoff SL. Primary venous aneurysms. Surgery 1990;108:9295.

7. Legnani G, Mettini L, Bonfioli C, Motta F. Venous aneurysm of extremities: a case report and literature review. Cardiovasc Surg 1995; 3:445-46.

8. Aldridge SC, Comerota AJ, Katz ML, Wolk JH, Goldman BI, White JV. Popliteal venous aneurysm: report of two cases and review of the world literature. J Vasc Surg1993;18:708-15.

9. Harolds JA, Friedman MH. Venous aneurysms. South Med J 1977;70:219-21.

10. Ross GJ, Violi L, Barder LW, Vujic I. Popliteal venous aneurysm. Radiology 1988;168:721-22.

11. Catherine S. Kim-Gavino, MD, Aruna Vade, MD,Jennifer Lim-Dunham, MD. Unusual Appearance of a Popliteal Venous Aneurysm in a 16-Year-Old Patient. Sonographic Findings. Journal of ultrasound in medicine: official journal of the American Institute of Ultrasound in Medicine 2007;25(12):1615-18.

12. Sirisinagandla SR, Pamidi N, Somayaji SN, Mohandas Rao KG. Right Popliteal Vein Aneurysm: A Case Report. International Journal of Anatomical Variations 2011;4:61-62.

13. Lawrence M. Gillman, Robert McGregor, Randy P. Guzman. Popliteal venous aneurysm and iliofemoralthrombosis. Can J Surg 2008; 51(1):17-18.

14. Fiori R, Chiappa R, Gaspari E, and Simonetti G. A Rare Case of Popliteal Venous Aneurysm. Case Reports in Medicine. doi:10.1155/2010/579256

15. Labropoulos N, Volteas SK, Giannoukas AD, Touloupakis E, Delis K, Nicolaides AN. Asymptomatic popliteal vein aneurysms. Vasc Endovascular Surg 1996;30:453-57. 
16. Watanabe A, Kusajima K, Aisaka N, Sugawara $H$, Tsunematsu $\mathrm{K}$. Idiopathic saccular azygos vein aneurysm. Ann Thorac Surg 1998;65:1459-61.

17. Helsted $M$, Vilmann $P$, Jacobsen $B$, Christoffersen JK. Popliteal venous aneurysms with or without pulmonary embolism. Eur J Vasc Surg 1991;5:333-42.

\section{ACKNOWLEDGEMENTS}

We are grateful to the cadaver donors who have voluntarily donated the same for the purpose of medical research.

\section{PEER REVIEW}

Not commissioned. Externally peer reviewed.

\section{CONFLICTS OF INTEREST}

The authors declare that they have no competing interests. 